\title{
The Design and Implementation of English Listening Question Bank and Dynamic Examination System Based on Internet
}

\author{
Donghui Shi ${ }^{1}$, Jorge Lopez-Vargas ${ }^{2}$, María del Carmen Cabrera Loayza ${ }^{2}$ \\ ${ }^{1}$ Department of Computer Engineering, School of Electronics and Information \\ Engineering - Anhui Jianzhu University, Hefei, China 230601 \\ Prometeo researcher, Universidad Técnica Particular de Loja, Ecuador \\ ${ }^{2}$ Departamento de Ciencias de la Computación -Universidad Técnica Particular de Loja, \\ San Cayetano Alto S/N, 1101608, Loja, Ecuador \\ sdonghui@gmail.com, jalopez2@utpl.edu.ec, mccabrerax@utpl.edu.ec
}

\begin{abstract}
In order to improve English listening teaching level and enhance students' listening capabilities, the paper proposes an English listening question bank and dynamic examination system. The listening bank can manage questions including audio materials collected by our univeristy. The dynamic examination system based on the question bank can randomly extract different types of questions from the bank according to the exam paper strategy. The system can generate an independent exam paper and a corresponding sound file for each student in an examination with the same exam paper strategy. It can avoid plagiarizing between students of adjacent seats. The developed system has been used in our university for two years. Three hundred students can take the examination at the same time using the exam papers and audio files generated by the system.
\end{abstract}

\section{Introduction}

At present, the traditional paper-based mode is mainly adopted in English listening examinations in most Chinese universities. The department of teaching management in the university needs to print a large number of exam papers before tests. When the English listening examination begins, teachers play the audio and students answer the questions on the exam paper. After the examination, teachers grade the exam paper manually. With the advancement of English teaching reform in Chinese universities, this pattern cannot adapt to the requirement for the modern English teaching. Therefore, English listening training should be improved in English teaching.

In recent years, some research and applications have been done in constructing the English listening question bank to improve the English listening teaching. Coniam et al. (2006) built an item bank of over 400 short listening items calibrated on item response theory principles. They extracted items from this bank for a traditional paperbased listening test and an adaptive computer-based test. Both the test forms are applied effectively in two classes of Grade 11 and Grade 12. The study by Al-Amri and Saad 
(2007) shows that none of the factors are found to have an influence on students' performance when doing the computer-based tests. Yan et al. (2009) illustrate the major principles of the test design. The authors think that the Internet-Based College English Tests have a positive impact on the reform of college English teaching and on the implementation of the computer and classroom-based college English teaching models. Kuo et al. (2010) propose that using partial dictation of an English teaching radio program to effectively improve students' comprehension ability. Díaz et al. (2011) introduce a new computerized adaptive test for the evaluation of English Listening. The bank is unidimensional and the items are satisfactorily fitted to the 3-parameter logistic model. Luján-García and Carmen (2011) analyze the potential capability of portable devices as useful tools in the process of learning foreign language. They state that the use of audio is very encouraging for teachers and students. Audio resources can be easily integrated into coursework and distributed. In recent years, some research and applications, for example, the study by Chen et al. (2012), have applied contextawareness techniques to help students learn without time or location constraints by using mobile devices and associated learning activities. These systems with advanced technologies are based on rich multimedia learning materials.

Although some commercial software systems could be available by purchasing from software companies, it is difficult to add new listening audio materials and satisfy the need of dynamic examination for our university using those existing software systems.

So we constructed an English listening question bank system to manage English listening audio materials collected by the school of foreign language in our university, and developed a dynamic examination system based on the listening question bank. The listening bank can also be provided for the other English learning systems, such as English learning apps, as a rich audio resource.

The paper is organized as follows. Section 2 introduces the system function and section 3 presents the system design and implementation. Finally, section 4 concludes the paper and proposes some probable directions in the future.

\section{System Function}

Figure 1 shows the work process of the system. The system uses Question management to add new questions including audio files and uses Exam paper management to add new exam papers. Exam paper strategy configuration is applied to set the parameters of the randomly selecting questions algorithm. After strategies are set, the system can generate an independent exam paper and a single audio file for each student in an examination using the same strategy. The system can provide the examination evaluation and analysis after the examination ends. The English listening question bank and dynamic examination system we developed mainly includes the following functions: Question management, Exam paper management, Exam paper strategy management and English listening dynamic examination. 
CBIE-LACLO 2015

Anais dos Workshops do IV Congresso Brasileiro de Informática na Educação (CBIE 2015)

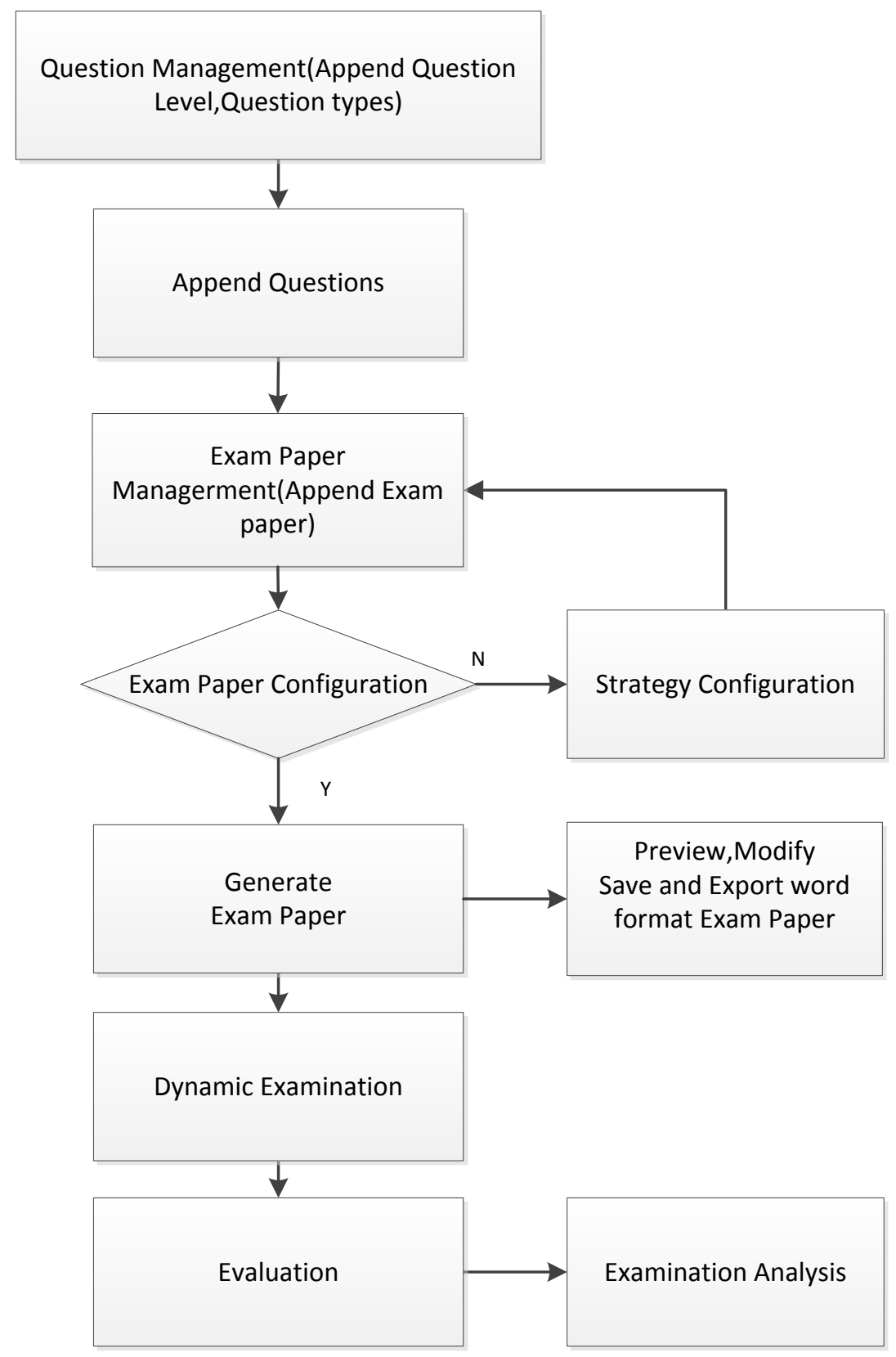

Figure 1. The work process of the system

\subsection{Question management}

The module can add questions including the audio files into the database. Each question has multiple properties which represent relevant information and classification standard. The properties are composed of Question Type, Difficulty Level, Score, Audio, Question Content and Question Answer. Question Type includes Sentences listening, Dialogue, Essay topic, Passage and words dictation, Compound dictation, Reading comprehension, Vocabulary and grammar, Close test, Short-answer questions and Writing. Among them, Sentences listening, Dialogue, Essay topic, Passage and Words dictation and Compound dictation are related to listening questions. Passage and word dictation, compound dictation, Short-answer questions and Writing belong to subjective 
questions, others are objective questions. Each question includes the properties of four difficulty levels and the knowledge points, such as sports, politics, economy etc.

\subsection{Exam paper management}

The module can add exam papers for different classes and levels. It can set the examination beginning time, duration, simulated training and formal examination. Selecting questions for an exam paper is completed by English listening exam paper strategy management.

\subsection{Exam paper strategy management}

The exam paper strategy which is the question extraction methods should be set before producing the new exam paper. The system generates the exam paper according to the strategy you set. Figure 2 shows the interface of exam paper strategy configuration. The parameters include number, score, pause time and order of every question types, percentages of different level questions. Questions can be selected randomly from the database and each question related to listening corresponds to an audio file or several audio files depending on question types. For example, each question of Sentences listening has five audio files. One is the audio file of the question and others are four audio files of four choices. The system merges all the independent audio files in a same question to generate a single audio file, then merges all the audio files of different questions form a whole audio file in question order. Each exam paper generated by the same strategy is different, and the audio file is also different. It can effectively avoid plagiarizing between students of adjacent seats. In addition, users can adjust the questions manually. The exam paper can be saved as a default or user-defined template of specific word file or directly generated as PDF files. Figure 3 is the interface of exam paper adjustment.

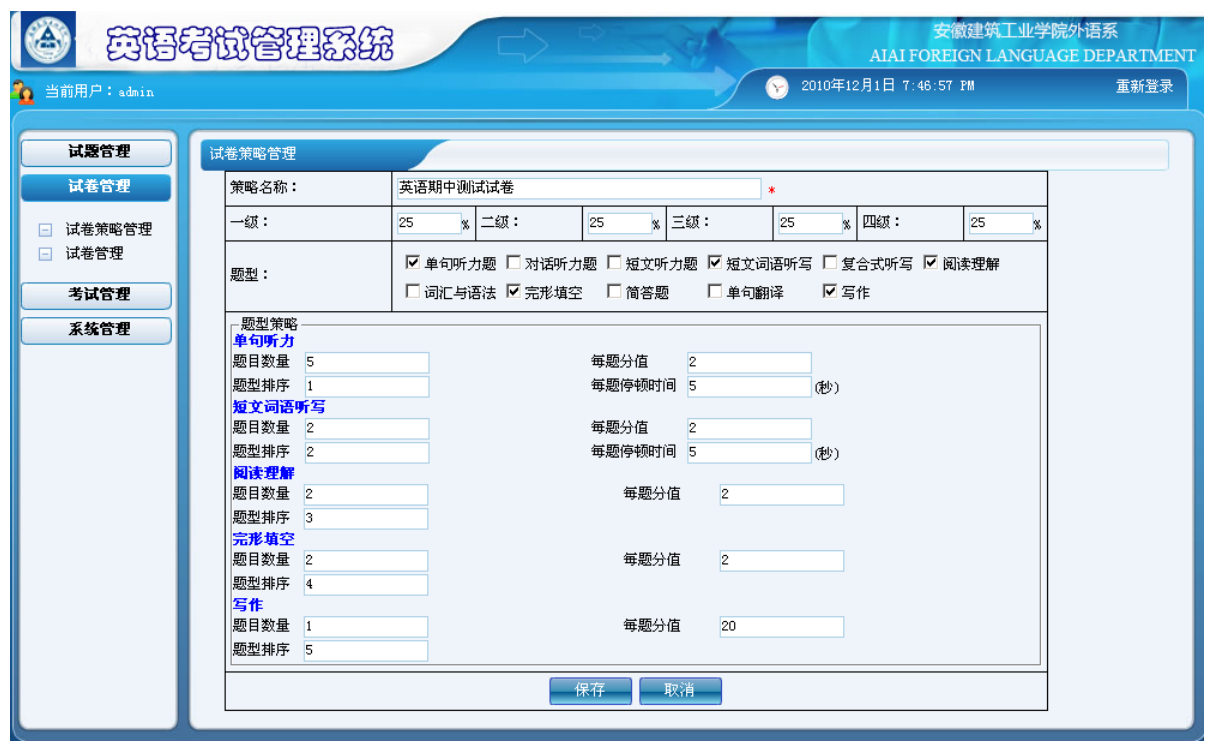

Figure 2. Exam paper strategy configuration 
CBIE-LACLO 2015

Anais dos Workshops do IV Congresso Brasileiro de Informática na Educação (CBIE 2015)

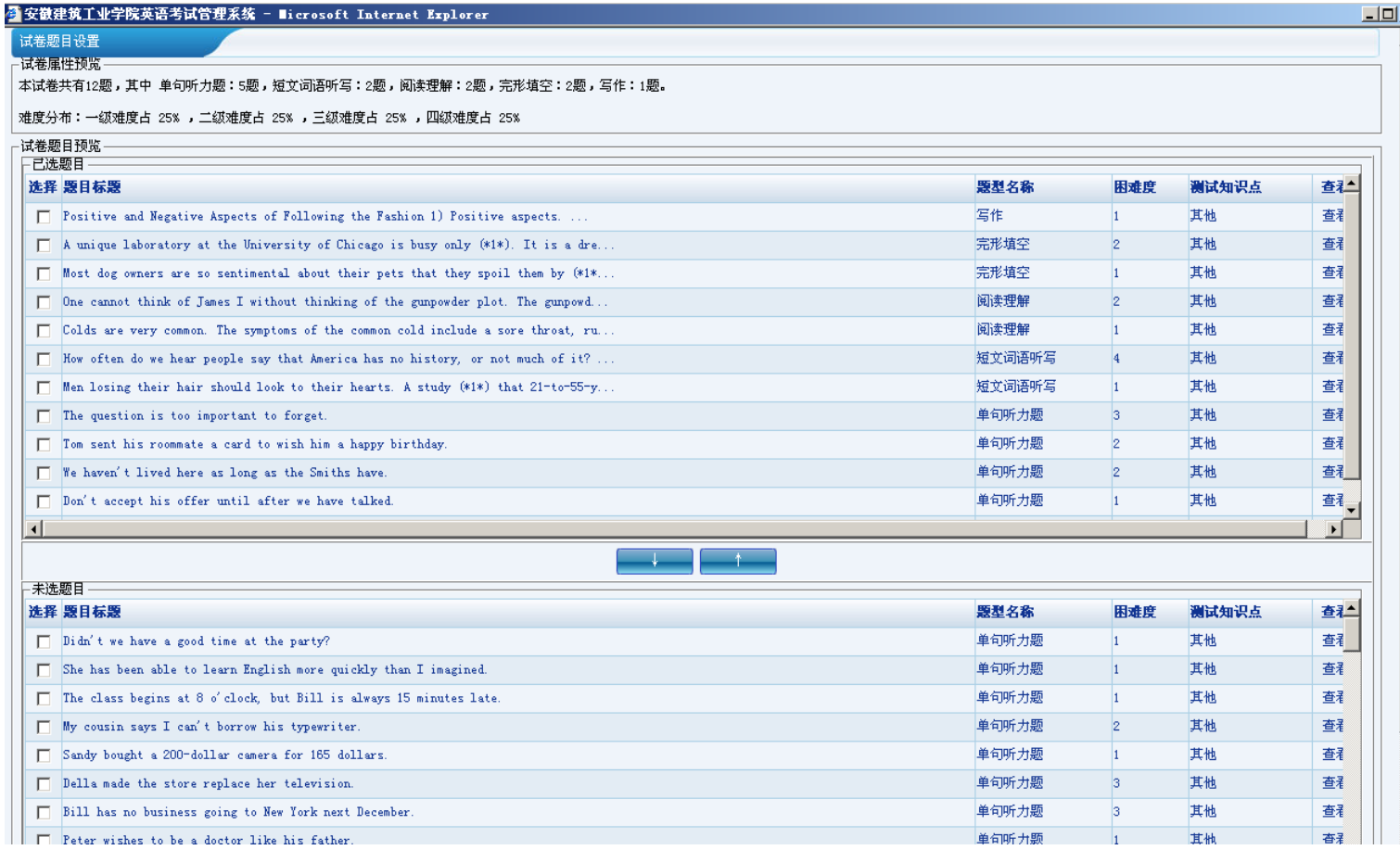

Figure 3. Exam paper adjustment

安徽建筑工业学院英语期中考试试卷刺时间: 119分53抄 考试时间120分钟满分134分

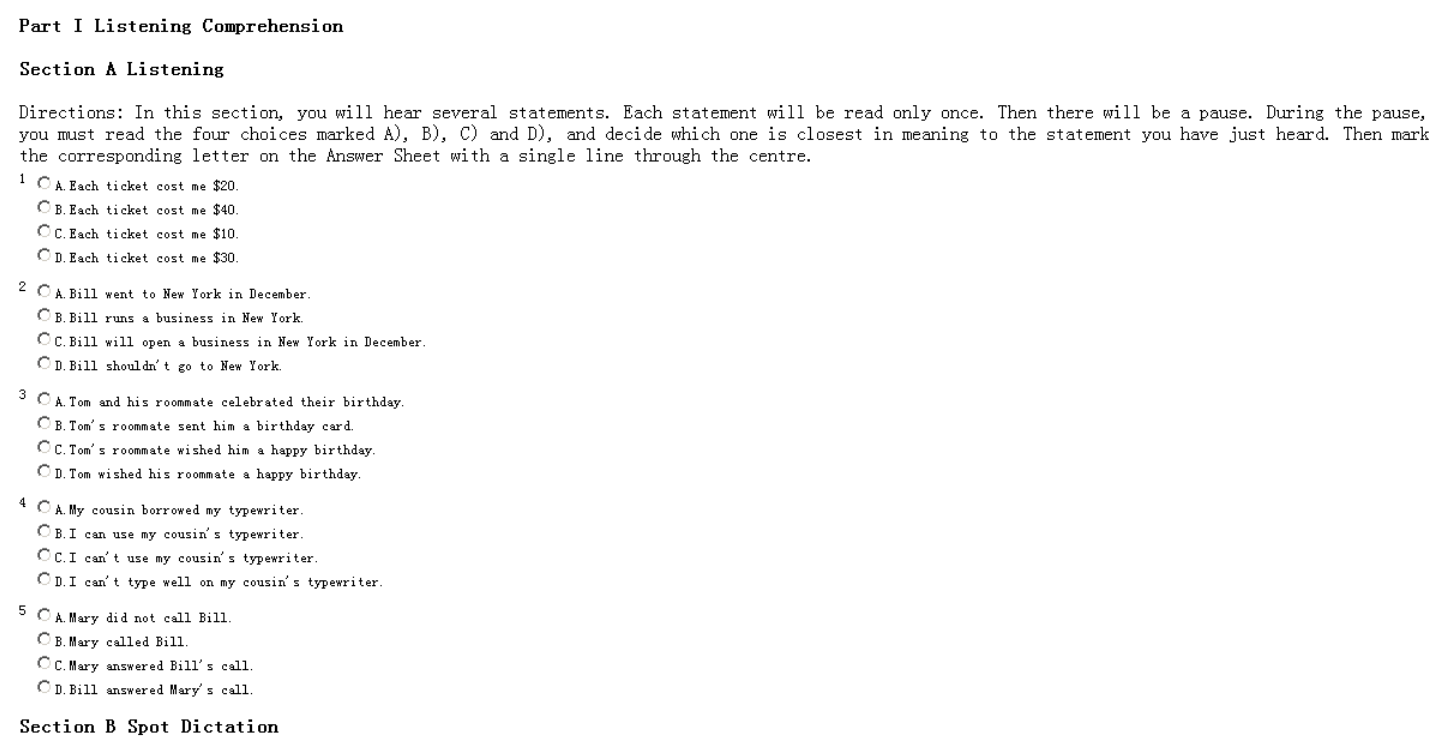

Directions: In this section, you will hear a passage three times. When the passage is read for the first time, you should listen carefully for its

Figure 4. The partial exam paper generated by the system

\subsection{English listening dynamic examination}

The system can be used in the internet environment and provide English listening dynamic examination, simulated training and examination analyzing functions. After students login in the system, they can use the exam papers and corresponding listening audio files generated dynamically. After students submit papers, objective questions can 
be graded automatically, and subjective questions need to be manually graded by teachers. Figure 4 shows the partial exam paper generated by the system.

\section{System design and implementation}

\subsection{System design}

The system uses .net 2008 as a development platform, SQLSERVER2005 as database, Windows XP Internet Explorer (IE) as the client, Windows2008 Server as the server and Internet Information Server (IIS) as the web server. Three-layer includes: presentation layer, database access layer, business logic layer. The technology of three layers was used in the software development. The system includes data access layer (DAL), business logic layer (BLL), and WEB. WEB project calls BLL, BLL project calls DAL, DAL project calls Model. The model is a mapping for the table of the database. For example, the dynamic examination program includes the files Creatpaper.aspx and Createpaper.aspx.cs. Creatpaper.aspx is a page file of ASP.NET Web and it is responsible for the interaction with users. CreatePaper.aspx.cs is a corresponding class file, and it consists of methods such as CreateQuestion()(Selecting the questions randomly), MergeWaveFile()(Merging the Wave files), ExamPaperSave()(Saving the examination records) etc. The methods call the Exam.BLL (the business logic layer file related to Examination), and Exam.BLL calls the Exam.DAL (the data access layer file related to Examination).

\subsection{Merging of audio files}

In the system, we use standard WAVE file format as the sound file. The WAVE file format [WAVE File Format 2015] is a subset of Microsoft's RIFF [RIFF Format 2015] specification for the storage of multimedia files. A RIFF file begins with a file header followed by a sequence of data chunks. A WAVE file is a RIFF file with a single "WAVE" chunk which consists of two sub-chunks -- a "fmt" chunk specifying the data format and a "data" chunk containing the actual sample data. Wave file headers follow the standard RIFF file format structure. The first 8 bytes in the file are the standard RIFF chunk header which has a chunk ID of "RIFF" and a chunk size is equal to the file size minus the 8 bytes used by the header. The parameters in a WAVE file format are listed in the Figure 5.

The method of merging WAVE files is to create only one header for all WAVE files from an exam paper then to write data of each file in a concatenated single file. For convenience, we require the users of the software to use the WAVE file format with the same parameters such as Num channels, SampleRate and BitsPerSample etc. When the users append the WAVE files into the database, some audio file convert tools can be 
CBIE-LACLO 2015

Anais dos Workshops do IV Congresso Brasileiro de Informática na Educação (CBIE 2015)

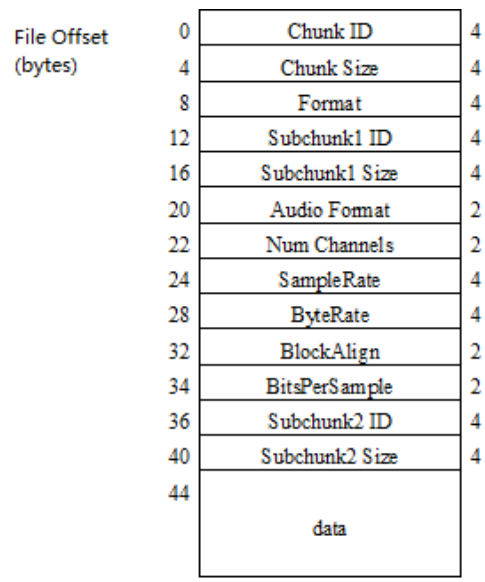

File Size

bytes

Figure 5. The WAVE file Format

used to unify the WAVE files to the same format.

Figure 6 shows the merging process of WAVE files with different types of questions. First, these WAVE files are extracted from the listening bank according to the exam paper strategy we have set. Then they are merged into a single WAVE file

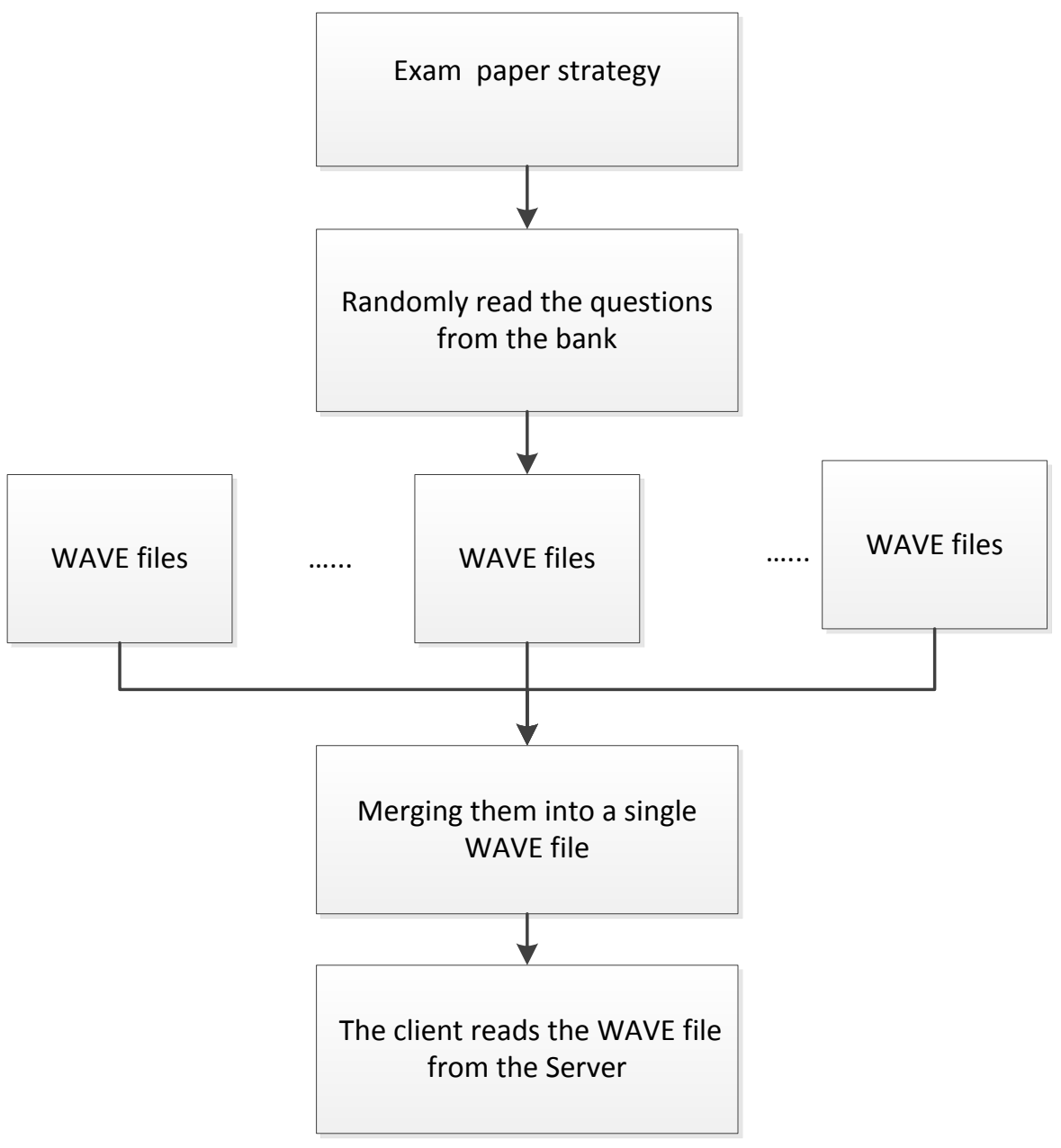

Figure 6. WAVE file merging process 


\section{CBIE-LACLO 2015}

Anais dos Workshops do IV Congresso Brasileiro de Informática na Educação (CBIE 2015)

using the merging algorithm. The single WAVE file is stored on the Server. The client can read the file from the Server. After the examination, the audio file generated will be deleted automatically to avoid too many files on the server.

The following lists the code fragment of MergeWaveFile(). It is used to generate a single WAVE file for the question type of Sentences listening. First, load all the audio files of the questions into memory. Then merge them sequentially with corresponding question numbers and questions. In the process, some pause time audio files are inserted at appropriate places in the audio file.

MergeWaveFile(string filename)

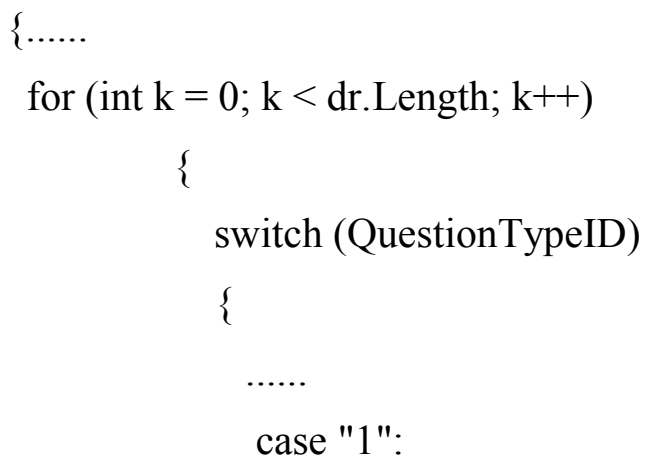

//Add the audio file of the pause time between different question types byte[] arrQuestionTypeDelay = GetFileByte(delayQuestionTypeFile); fileByte.Add(arrQuestionTypeDelay); 
CBIE-LACLO 2015

Anais dos Workshops do IV Congresso Brasileiro de Informática na Educação (CBIE 2015)

//Merge the whole audio file

wave.Merge(fileByte, headFile, filename);

\}

\}

\section{Conclusion}

The paper introduces an English listening question bank and dynamic examination system, and illustrates the design of the system and the implementation of the key technologies. The question bank system can manage the English learning audio files. The dynamic examination system can generate an exam paper and a single WAVE file from all the WAVE files corresponding to an exam paper for a single user.

The system has been used in English listening examinations for all the students in our university for two years, and it has good efficiency in generating exam papers and audio files randomly. Three hundreds of students can use the dynamic examination at the same time steadily. The using of dynamic examination system greatly urges students to practice their English listening. By analyzing the student scores provided by the system, we found most students' testing scores were improved significantly. The effectiveness of the system was verified. In the campus, students can also use the system as English listening simulation training system. In order to ensure the system to have good effects, a great number of English listening materials are added into the question bank continually.

In the future, we will make full use of the English listening bank, extend the system to the smart phone applications and open to Internet users outside the campus. We have accumulated a large volume of examination information related to examinations and learning records. The big data technology can be used in analyzing the data of the examination and simulation training to help us find better ways to enhance the English listening capabilities of students and improve the quality of English listening teaching.

\section{Acknowledgment}

This work was funded by the Prometeo Project of the Secretariat for Higher Education, Science, Technology and Innovation of the Republic of Ecuador. This work was also supported by Anhui Provincial Natural Science Foundation of China (1508085MF114), Technology Foundation for Selected Overseas Chinese Scholar (2014), Provincial Quality Project of Anhui Province Education Department of China (2013jyxm157) and National bilingual teaching demonstration course project of China Education Department(2009).

\section{References}

Al-Amri, Saad. (2007) "Computer-based vs. Paper-based Testing: Does the test administration mode matter?" 11th CAA International Computer Assisted Conference. Proceedings of the Conference on 10th \&11th July 2007. Loughborough University,Loughborough, pp.3-13 
Chen, Chia-Chen, and Tien-Chi Huang (2012). "Learning in a u-Museum: Developing a context-aware ubiquitous learning environment." Computers \& Education 59, no.3 pp.873-883.

Coniam, David. (2006) "Evaluating computer-based and paper-based versions of an English-language listening test." ReCALL 18, no. 02, pp.193-211.

Díaz, Julio Olea, Francisco José Abad, Vicente Ponsoda Gil, Juan Ramón Barrada, and David Aguado García. (2011) "eCAT-Listening: Design and psychometric properties of a computerized adaptive test on English Listening." Psicothema 23, no. 4,pp.802807.

Kuo, Yihsiang. (2010) "Using partial dictation of an English teaching radio program to enhance EFL learners' listening comprehension." Asian EFL Journal Professional Teaching Articles 47. pp.4-29.

Luján-García, Carmen. (2011) "Exploring the Use of Audio Files in Foreign Language Mobile Learning: Tips for Educational Practitioners Florence Lojacono." Frontiers of Language and Teaching, Vol. 2: Proceedings of the 2011 International Online Language Conference (IOLC 2011). Universal-Publishers.

RIFF Format Reference. http://netghost.narod.ru/gff/graphics/summary/micriff.htm In May 12, 2015

WAVE File Format. http://www.lightlink.com/tjweber/StripWav/WAVE.html In May 12,2015

Yan, Jin, and Wu Jiang. (2009) "Design principles of the Internet-Based College English Test [J]." Foreign Language World 4: 009. 